\title{
Prevention of mine gas disasters in coal mine
}

\author{
Pinghuai $\mathrm{Mao}^{\mathrm{a}, 1}$, Yilin Mao ${ }^{\mathrm{b}, 2}$, Shuai Zhang ${ }^{\mathrm{a}, \mathrm{c}, 3}$, Yongyuan $\mathrm{Fu}^{\mathrm{c}, 3}$
}

\author{
${ }^{a}$ School of Mechanical Engineering, Anhui University of Science and Technology, Huainan, China \\ ${ }^{\mathrm{b}}$ The Internet of Things Institute, CASC \\ ${ }^{\mathrm{c}}$ School of mechanical Engineering Anhui University of Science and Technology Huainan \& Product \\ Quality Supervision and Inspection in Huainan of Anhui province

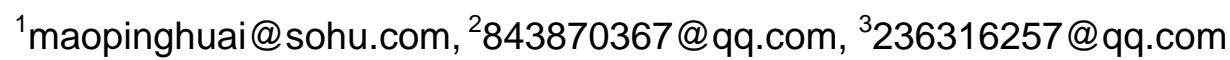

Keyword: Mash gas, Safety, Computer monitoring, Prevent accidents highlight

\begin{abstract}
Our mines are underground mining, poor condition. Gas explosion, dust explosion, coal and gas outburst, fires and other accidents have occurred in which gas explosion was the most common, is one of the biggest causes of death and property damage. Accident statistics from related departments, gas explosions have accounted for seven in the coal accidents in which ten or more people was killed, it was known as the "king of mine disasters". Therefore, the analysis gas explosion causes and takes appropriate countermeasures is especially important.
\end{abstract}

\section{Introduction}

We have to improve the safety factor to make sure that workers can work at ease, in order to contribute to the economic and coal mine production. We need to deal with prevent accidents highlight from both staff and facilities to deal with.

Personnel must first improve their safety awareness, regular safety education; safety philosophy is always to work through. To set up a safety oversight system, personnel should regularly check the value of various indicators and the situation appears to be a timely manner. Antithesis of facilities, such as boring machine, coal mining, hydraulic piping, ventilation systems, etc, should be schedule maintenance and inspected to prevent leakage, leakage and other dangerous situations. When a situation occurs in a timely manner to turn off the mechanical power can be produced only eliminate the hazard [1].

In terms of facilities, there must be able to effectively discharge gas ventilation system must work and the spare. A working fan displacement and power should be large enough. In terms of facilities but also have some instruments, such as monitoring instruments.

\section{Mash gas explosion conditions}

Typically mash gas explosion needs to meet three conditions: the concentration of the gas, the concentration of oxygen and ignition temperature range.

\section{Mash gas concentration}

Mash gas explosions have certain concentration range, we put the mash gas in the air can cause a range of concentrations ashes explosion called a mash gas explosion limits. Mash gas explosion limit of $5 \%$ to $16 \%$, when the mash gas concentration is less than $5 \%$, a fire or explosion, the burning layer can be formed in the periphery of the flame when the mash gas concentration of 9.5\%, the largest of its explosive power (oxygen and mash gas completely reaction) mash gas concentration in the more than 16 percent, losing its explosive, but still in the air, a fire burning ${ }^{[2]}$.

\section{Oxygen concentration}

The study found that when the oxygen concentration in the underground tunnel smaller, limit the smaller mash gas explosion occurred when the concentration is less than $10 \%$, the mash gas cannot be ignited and, thus, eliminate the mash gas explosion occurred, if higher than this the boundaries, 
the other conditions are right, it is prone to mash gas explosion.

\section{Ignition temperature range}

Ignition temperature of the mash gas explosion is another condition required temperature range of control and monitoring is of great significance in reducing mash gas explosion, generally speaking, the minimum temperature range of the mash gas explosion is $600{ }^{\circ} \mathrm{C} \sim 700{ }^{\circ} \mathrm{C}$. Through long-term study found that when the mash gas pressure increases, will result in reduced ignition temperature; ignition temperature at a certain time, the fire source area, for a long time, it tends to cause combustion of the mash gas, which exploded. So, when the underground work must be carried out in accordance with the rules and regulations, you cannot carry items caused the fire source, thus ensuring the safety of them and others, to avoid mash gas explosion occurred.

\section{Mash gas prediction and detection}

\section{Mash gas prediction}

Mash gas control, you must first predict the amount of gas emission; gas emission prediction is to get some data, and then use these data to mine gas drainage, mine ventilation. Prediction method of gas are mainly mining rule and sub source prediction method.

\section{Mine statistical method}

The reality mining statistical methods applied in the amount of mine gas leaking material calculated gas emissions come with mining depth analysis of the law, to calculate the amount of gas emission from new wells.

The basic formula

$$
q=\left(H-H_{0}\right) / \mathrm{A}+2
$$

(1)

Where: q- Mining area or face amount of the average value of gas emission units; H- Depth, units; H- Gas weathered zone depth, units; A- Mining depth ratio of gas emission units.

Take mine statistical methods conditions:

1) When predicting production of the mine mash gas emissions in new mines on the side of the old mine, geological and production conditions must be guaranteed with the same or similar to the original.

2) Before the first caving, because the gas concentration does not reach normal, so this time it cannot be measured over Gas Emission for statistics.

3) Not all q and H ratio is constant, so first make sure the actual situation according to the degree of extraction and the ratio of the amount of gas leaking shift with mining depth of habit.

4) Gas emission, which does not enter the normal amount from coal mining segment, cannot be used for statistics.

5) Gas drainage also has an impact on the amount of gas emission, so it need be taken into account.

\section{Prediction based on respective method}

Using prediction based on respective method to calculate mine gas leakage, in accordance with this layer contains a gas of coal underground mining technology and how the condition, is based on the fundamental gas leaking gas for each source of emission law, calculated using the formula emission gas ${ }^{[3]}$.

The basic formula

1) Gas Emission when coal or thick coal seam mining

$q_{1}=k_{1} \cdot k_{2} \cdot k_{3} \frac{m_{0}}{m_{1}} \cdot\left(X_{0}-X_{1}\right)$

2) Gas emission when thick coal seam mining

$q_{2}=k_{1} \cdot k_{2} \cdot k_{3} k_{f i} \cdot\left(X_{0}-X_{1}\right)$

3) Gas Emission of adjacent layers of coal 
$q_{3}=\sum_{i=1}^{n} \frac{m_{i}}{m_{1}} \cdot k_{i} \cdot\left(X_{0 i}-X_{1 i}\right)$

\section{Mash Gas Detection}

Establish mash gas monitoring systems, automatic mash gas detection and alarm equipment disconnect device, to achieve ground central station computer monitoring, and strengthen management, give full play to its performance and role, but with full-time workers to check the gas concentration gas inspection with an optical gas test, thus automatically detection and manual inspection "dual monitors" ${ }^{[4]}$.

\section{Control mash gas and air mass ratio method}

Since the gas must meet three conditions before the explosion, so we prevent a gas explosion, usually three aspects of control to control the gas disaster occurred from reasonable regulation of gas and air-mass ratio and ignition sources.

The main treatment methods of mash gas and air mass ratio

The main method of mash gas and air mass ratio include drainage in the lower band, a ceiling drainage in theory and front and rear boundaries and so on ${ }^{[5]}$.

1) Drainage in the lower band. Drainage in the theoretical lower limit of the band, are generally higher than the height of the caving zone recovery.

2) Drainage in with the ceiling. Generally, the sealing effect is to exclude influence of the higher layers, drainage concentration is higher, however, the smaller the mixing amount of drainage. Experience has shown that is not within the scope of fractured zone, you can get good drainage effect.

3) Theoretical front and rear boundaries (Drainage in the band). Drainage in with: front boundary theory, the work is located within a few meters in front of square; Drainage in with: theory behind the boundaries, to face the rear of tens of meters or so.

\section{Analysis of the mine gas explosion source}

Coal mining depth in China is more and more deep, the pressure is increasing inevitable with the increase of depth, because of the great depth and great pressure, in the process of formation of the coal gas is processed between coal gaps, but due to the depth and pressure, gas is not easy to shed, in deep coal seam, gas is also present at high concentration. It will bring immeasurable disaster if we lack of understanding of the source of fire ${ }^{[6]}$.

\section{Treatment method of fire source}

One of the five coal mine natural disasters: spontaneous combustion of coal mine, the key to solve the problem of coal spontaneous combustion of coal spontaneous combustion is determined in advance the hidden location of fire source position. Because the coal burning fire, strong concealment, inside and outside the country, still no an effective detection method is used to determine the ignition sources are mainly electric spark, mine machinery mainly adopts hydraulic machinery can reduce the electric spark, but the mine electric equipment to support building protection against electric spark.

\section{Improved ventilation system}

Improvement of ventilation system is actually the control of gas and air mass ratio, but due to improved ventilation system can greatly reduce the incidence of gas disasters, so this paper emphasizes this especially. Mine ventilation system is like the human respiratory system, the construction personnel mine, ventilation system is the guarantee of life, and reasonable ventilation system for the prevention and control of coal mine gas explosion has a very important role, therefore, before the coal mining must be carried out before the design of the ventilation system that is advanced construction.

\section{Conclusions}

To record the common problems of mining coal seam and finish it up to focus on the work of inspection of this risk factor is high on the list of places to check. Workers will standardize 
operational processes when a regular inspection of a good working system is established. Ventilation systems are not sloppy place, should improve the ventilation system, should ensure that the needs of the time must have ventilation fans in normal work, and complete gas emissions. Construction of highly qualified personnel is also essential; you can choose from college graduates annually the effectiveness of talent for the company. Regular staff training expertise, excellent staff of special schools can also be sent to retraining. Build a strong talent is definitely less.

\section{References}

[1] Nannan Liu, Xinrong Zhou. On the eco-environmental effects of mining and their ecological restoration [J], Heilongjiang scientific and technological information,2010(10):5-6

[2] Cai Zhao-jin. On China's coal mine safety monitoring system [J] modern coal mines, 2006, (03)

[3] W M Cao. The iimplementations of research methods and safety inspection process. China Safety and environmental engineering [J], 2010(17): 92-94.

[4]Erik K Hendriksen. Jig and Fixture Design Manual. Industrial Press Inc, 2010

[5] The Measurement Setup for Gas Detection by Resistance Fluctuations of Gas SensorsSmulko

[J], Instrumentation and Measurement Technology Conference,2006.IMTC 2006.Proceedings of the IEEE24-27 April 2006 Page(s)

[6]Soon Chong Johnson Lim,Ying Liu,Wing Bun Lee.A Methodology For Building A Semantically Annotated Multi-Faceted Ontology For Product Family Modelling[J]. Advanced Engineering Infor matics 2011 (25 ) :147-161. 